\title{
HMGB1 induces the overexpression of miR-222 and miR-221 and increases growth and motility in papillary thyroid cancer cells
}

\author{
STEFANIA MARDENTE ${ }^{1}$, EMANUELA MARI $^{1}$, FABRIZIO CONSORTI $^{2}$, CIRA DI GIOIA $^{4}$, RODOLFO NEGRI $^{3}$, \\ MARILENA ETNA $^{3}$, ALESSANDRA ZICARI ${ }^{1}$ and ALFREDO ANTONACI ${ }^{2}$ \\ Departments of ${ }^{1}$ Experimental Medicine, ${ }^{2}$ Surgery 'F. Durante', ${ }^{3}$ Biology and Biotechnology 'Charles Darwin', \\ and ${ }^{4}$ Radiology, Oncology and Pathology, Sapienza University of Rome, I-00161 Rome, Italy
}

Received July 9, 2012; Accepted August 22, 2012

DOI: $10.3892 /$ or.2012.2058

\begin{abstract}
Experimental and epidemiological studies have revealed that chronic inflammation contributes to cancer progression and even predisposes to cellular transformation. Inflammatory infiltrates in papillary thyroid cancer include lymphocytes, macrophages and cytokines. High-mobility group box 1 protein (HMGB1) is a late inflammatory cytokine that signals danger to the immune system through the receptor for advanced glycation end-products (RAGE) and Toll-like receptor. The activation of the above receptors results in the secretion of growth, chemotactic and angiogenic factors that contribute to chronic inflammation. In this study, we suggest that apart from the activation of signal transduction pathways by the activation of RAGE, the indirect inhibition of cell cycle regulators [such as phosphatase and tensin homolog (PTEN)] may also cause an increase in cell growth and motility. MicroRNAs (miRNAs) have increasingly been implicated in regulating the malignant progression of cancer. MiR-221 and miR-222 have been found to be deregulated in human papillary thyroid carcinomas. They are involved in cell proliferation through the inhibition of the cell cycle regulator, $\mathrm{p} 27^{\mathrm{kip} 1}$, in human papillary carcinomas. In this study, we show that HMGB1 increases the expression of miR-221 and miR-222 in primary cultures of excised papillary lesions and in an established papillary cancer cell line (BC PAP). The overexpression of oncogenic miR-221 and miR-222 caused by HMGB1 is associated with an increase in malignancy scores, namely cell growth and motility.
\end{abstract}

\section{Introduction}

High-mobility group box 1 protein (HMGB1) is a pro-inflammatory cytokine that can either be passively secreted by necrotic

Correspondence to: Dr Stefania Mardente, Department of Experimental Medicine, Sapienza University of Rome, Viale Regina Elena 324, I-00161 Rome, Italy

E-mail: stefania.mardente@uniroma1.it

Key words: microRNAs, high-mobility group box 1 protein, receptor for advanced glycation end-products, papillary cancer, chemotaxis cells or actively secreted in response to inflammatory signals. In our previous study, we showed that HMGB1 is overexpressed in thyroiditis and in papillary thyroid cancer (1). HMGB1 can be actively secreted by a variety of cells including macrophages, activated monocytes, dendritic cells, endothelial cells and certain cancer cells (2). It functions as an alarmin and its extracellular release signals damage to the immune system. HMGB1 signals through the receptor for advanced glycation end-products (RAGE) and via Toll-like receptor (TLR)2 and TLR4. The activation of these receptors results in the activation of $\mathrm{NF \kappa B}$ which induces the secretion of cytokines, growth factors (3) and angiogenic factors (4). Apart from its connection to NFאB, RAGE activation is linked to many signaling pathways that upregulate protein synthesis, cell survival, proliferation and movement. In certain cases $\mathrm{NF} \kappa \mathrm{B}$ may enhance the expression of oncogenic factors, such as microRNAs (miRNAs) (5). The intracellular pathways starting from different kinases (MAPKs) (6), PI3K/ AKT (7), JAK/STAT (8) that converge on AKT are positively or negatively controlled by oncogenes or tumor suppressor genes (9) which are in turn enhanced or inhibited by various factors, such as miRNAs. miRNAs are small non-coding RNAs that control gene expression at the post-transcriptional level by targeting mRNAs. They have been shown to play an important role in various processes, such as cellular development, proliferation and apoptosis (10). Their aberrant expression has been linked to several human cancers and metastasis (11). Some of them function as oncogenes or tumor suppressors (12). MiR-221 and -222 have been found to be deregulated in human papillary thyroid carcinomas (13) and are involved in thyroid cell transformation as well as cell proliferation through the inhibition of a cell cycle regulator (p27 $\left.{ }^{\mathrm{kip} 1}\right)$ (14). A single miRNA can regulate different target genes as perfect complementarity is not required. Many miRNAs such as miR-221 and -222 form genetic clusters and therefore exert co-ordinated expression and function. In gastric cancer cells for example, the miR-221/222 cluster has been shown to target the tumor suppressor gene, phosphatase and tensin homolog (PTEN), resulting in an increase in cancer cell proliferation and radio resistance (15).

We have previously demonstrated $(1,3)$ that inflammatory infiltrates are present in papillary cancer and may contribute to tumor transformation and escape from immune surveillance. We showed that HMGB1 is overexpressed in the papillary cancer microenvironment. In this study, we analyzed the influ- 
ence of HMGB1 on the expression of the miR-221/222 cluster in a papillary cancer cell line and in primary cultures of thyreocytes obtained from patients who underwent thyroidectomy for papillary cancer.

\section{Materials and methods}

Cell lines. The long-term thyroid carcinoma cell line, BC PAP (16), was kindly provided by Professor M. Russo (University of Sapienza, Rome, Italy) and maintained in RPMI-1640 (Gibco) supplemented with heat inactivated $10 \%$ FCS containing $2 \mathrm{mM}$ L-glutamine.

Patients and collection of samples. Patients included in this study were selected from a group of 30 patients with papillary cancer who had undergone total thyroidectomy for a preoperative diagnosis of thyroid cancer. All patients provided written informed consent, agreeing to participate in this study, in accordance with the ethical standards of our institution. Standard histology confirmed the diagnosis and allowed us to select 11 patients ( 7 females and 4 males, aged from 28 to 73 years) of which 9 were used for the preparation of primary cultures as previously described (1) and 2 female patients with papillary cancer (pT3NxMx) were selected for chemotaxis experiments.

Primary cultures. Normal and neoplastic thyroid specimens were obtained from patients who had undergone surgical treatment at the Department of Surgery at our institution. Histological classification was carried out in accordance with the WHO recommendations. Upon removal, specimens were divided into 2 groups: in the first group, the samples were processed for routine histopathological examination and in the other group, the samples were used for establishing primary short-term cultures as previously described (1). Cells were cultured for $24 \mathrm{~h}$ in RPMI at $37^{\circ} \mathrm{C}, 5 \% \mathrm{CO}_{2}$. Where required, $10 \mathrm{nM}$ HMGB1 (Sigma) were added to the cultures. Cell viability, determined by the Trypan blue exclusion test, was always $95-98 \%$.

Monocytes were obtained from healthy donors by the monocyte isolation method. Human peripheral blood mononuclear cells (PBMCs) from buffy coats, obtained from healthy donors, were isolated by Lymphoprep (Nycomed AS Pharma Diagnostic Division, Oslo, Norway) density-gradient centrifugation, washed 3 times in PBS, pH 7.4, and isolated by density gradient separation (Lympholite; Cedarlane, Ontario, Canada). $\mathrm{CD}_{14}{ }^{+}$monocytes were purified by incubation with antiCD14-coated microbeads (Miltenyi Biotec, Bergish Gladbach, Germany), followed by sorting with a magnetic device (MiniMacs Separation Unit; Miltenyi Biotec), according to the manufacturer's instructions.

The purity of the isolated monocytes was evaluated by staining with a fluorescein isothiocyanate-conjugated antibody against monocytes (FITC-conjugated anti-CD14) and analysis by flow cytometry. Viable monocytic cells $(86.7+3 \%)$ (mean \pm SEM) were obtained. Cells were cultured for $4 \mathrm{~h}$ in RPMI-1640, containing $2 \mathrm{mM} \mathrm{L}$-glutamine, $100 \mathrm{U} / \mathrm{ml}$ penicillin, $100 \mathrm{mg} / \mathrm{ml}$ streptomycin, and $250 \mathrm{pg} / \mathrm{ml}$ Fungizone (Gibco), in the absence of antioxidant agents, at $37^{\circ} \mathrm{C}$ in a humified $5 \% \mathrm{CO}_{2}$ atmosphere before the assay. U937, a well-established cell line derived from human monocytic leukemia was used as the positive control for western blot analysis.

Chemotaxis. Cell migration was assessed in the BC PAP cells, in primary cultures from 2 patients with papillary cancer. Specimens were obtained from nodules and healthy contralateral lobes. Monocytes from healthy donors were used as the positive controls. The cells were seeded on a 24-well migration plate (ECM 509; Chemicon International). The assay is based on the Boyden chamber principle. It provides a system for quantitative determination of cells migrating through $8-\mu \mathrm{m}$ porous membrane towards a chemotactic agent. In our case the lower chamber was loaded with RPMI medium with or without $10 \mu \mathrm{M}$ HMGB1 (Sigma). Incubation was carried out at $37^{\circ} \mathrm{C}$, $5 \% \mathrm{CO}_{2}$ for $12 \mathrm{~h}$. At the end of the incubation time, migration inserts were removed from the migration chambers, placed into wells containing cell detachment solution and lysed. Samples were dyed and read with a photometric plate reader using a 480-nm filter set. Samples without cells but containing cell detachment buffer, lysis buffer and the dye were used as the blank controls for interpretation of the data.

Western blot analysis. Whole cell lysates were separated as previously described (1) on 15\% SDS-polyacrylamide electroforesis gel for HMGB1 and 10\% for RAGE. Samples were heat-denatured for $5 \mathrm{~min}$, loaded on standard Tris- $\mathrm{HCl}$ polyacrylamide gel and run on ice at $40 \mathrm{~V}$ for the stacking gel and $80 \mathrm{~V}$ for the running gel. Proteins were transferred onto a PVDF membrane (Bio-Rad, Hercules), previously activated in $100 \%$ methanol for $15 \mathrm{sec}$. The membrane was blocked in TBS-T and 5\% albumin for $1 \mathrm{~h}$, probed overnight at $4^{\circ} \mathrm{C}$ by the specific antibody (monoclonal anti-HMGB1 by Sigma and monoclonal anti-RAGE (Millipore). At the end of the incubation time, the membrane was washed and incubated with anti-mouse $\mathrm{IgG}$ peroxidase conjugated secondary antibodies (1:10000 Sigma) for $1 \mathrm{~h}$ at room temperature. The signal was detected by autoradiography (Kodak Biomax light film; SigmaAldrich) using the chemiluminescent peroxidase substrate kit (Sigma-Aldrich) then quantified by densitometric analysis using software (Quantity-One, Bio-Rad).

MiRNA relative quantification by real-time RT-PCR. Total RNA was extracted from the cells using TRIzol reagent (Life Technologies), according to the manufacturer's instructions.

TaqMan ${ }^{\circledR}$ microRNA assays (Applied Biosystems, Foster City, CA, USA) that included RT primers and TaqMan probes were used for reverse transcription and to quantify the expression of mature miR-221 and -222 in the tissue samples and cell lines. The ubiquitously expressed U6b small nuclear RNA (snRNA) was used as the internal control. Relative quantification was calculated using the $\Delta \mathrm{Ct}$ method.

\section{Results}

$B C P A P$ cells express HMGB1 and RAGE receptors. We previously (1) provided evidence that thyreocytes from papillary cancer and thyroiditis express HMGB1. We also demonstrated that the inflammatory microenvironment in thyroiditis contributes to neoplastic transformation. Therefore, we aimed to investigate whether HMGB1 can be produced by a papillary 


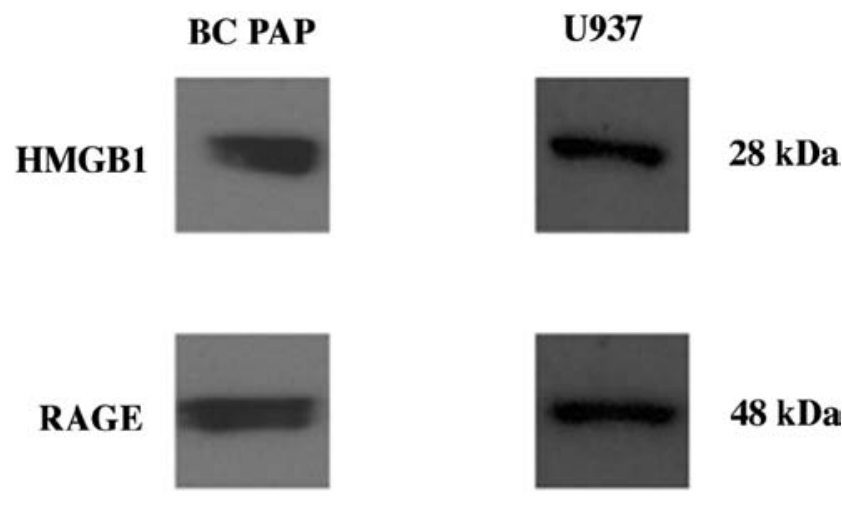

Figure 1. Expression of HMGB1 $(28 \mathrm{kDa})$ and RAGE $(48 \mathrm{kDa})$ in BC PAP cells. The U937 cell line was used as the positive control. A representative experiment is shown.

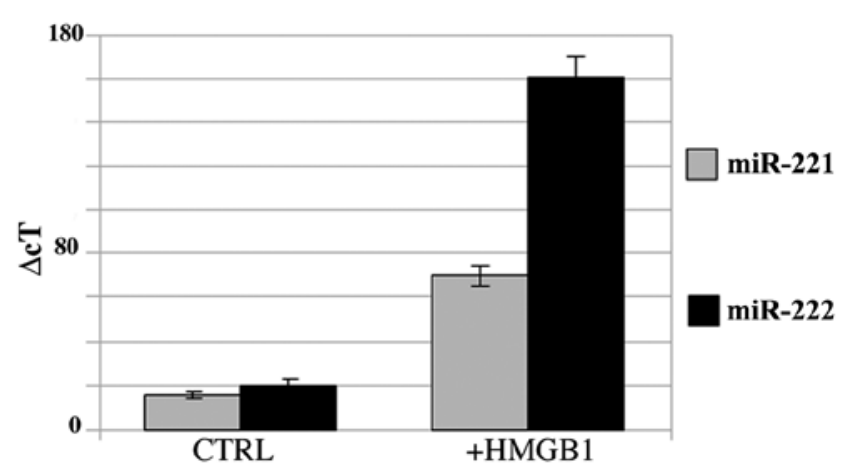

Figure 2. Expression of miR-222 in BC PAP cells. Cells were cultured with or without [control cells (CTRL)] HMGB1 for $24 \mathrm{~h}$. Results are expressed as $\Delta \mathrm{Ct}$ (compared to U6 snRNA).

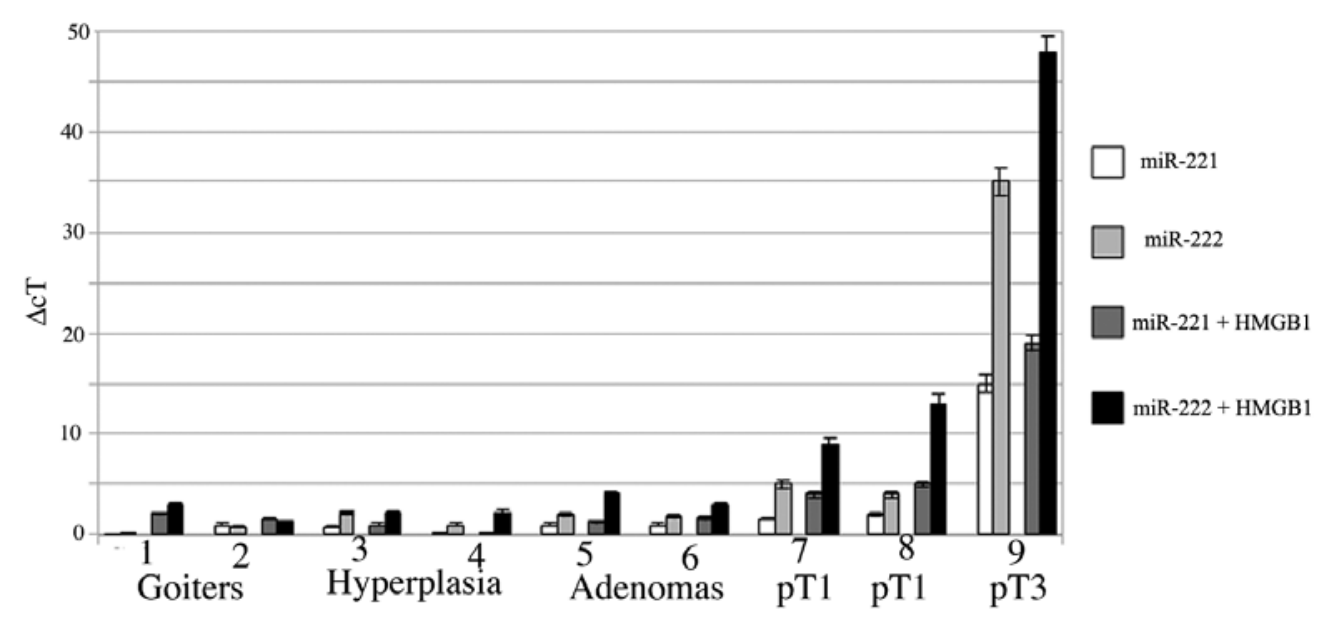

Figure 3. Expression of miR-221 and -222 in primary cultures of thyreocytes obtained from patients with goiters (columns 1 and 2), hyperplasia (columns 3 and 4), adenoma (columns 5 and 6), pT1 (columns 7 and 8) and pT3 (column 9). Cells were cultured with or without [control cells (CTRL)] HMGB1 for 24 h. Results are expressed as $\Delta \mathrm{Ct}$ (compared to U6 snRNA).

cancer cell line. Fig. 1 shows that BC PAP cells express both HMGB1 and RAGE. This suggests that HMGB1 can bind to RAGE receptors. The activation of RAGE activates the intracellular signal transduction pathways, leading to various stimulatory functions.

HMGB1 modulates the expression of miR-221 and miR-222 in $B C P A P$ cells and in primary cultures of papillary cancer cells. BC PAP cells express miR-221 and -222 as shown in Fig. 2. The addition of HMGB1 to the culture medium increased the expression of miR-221 (3-fold increase) and miR-222 (7-fold increase).

A particularly interesting result was obtained in the thyreocytes from patients with papillary tumors, with adenomas and micro-macrofollicular goiters. Fig. 3 shows a comparative analysis of the expression of miR-221 and miR-222 in primary short-term cultures treated with $10 \mu \mathrm{M}$ HMGB1. The expression of miR-221 and -222 was low in the goiters, as well as in the samples of hyperplasia and adenoma, even though the addition of HMGB1 led to an increase in the expression of miR-222. This positive trend was higher in the primary cultures of papil- lary cancers and it reached its peak in the papillary cancer (pT3) sample.

$H M G B 1$ increases cell growth in BC PAP cells. In order to investigate whether HMGB1 promotes growth in BC PAP cells, we performed cell growth studies by seeding $10^{5}$ cells in 24-microwell plates in the presence of $10 \mu \mathrm{M}$ HMGB1. As shown in Fig. 4, HMGB1 increased cell growth after $24 \mathrm{~h}$ (2-fold) and at 48 and $72 \mathrm{~h}$ (1.5-fold). Cell mortality increased in the controls and stimulated cells with a small but not significant difference in the 2 populations, possibly due to overcrowding in the plates resulting from the high growth rate.

HMGB1 induces chemotaxis in papillary cancer cells and in BC PAP cells. Cell migration was assessed in the BC PAP cells in primary cultures from 2 patients with papillary cancer (pT3) and in cells from healthy lobes from the same patients. Monocytes from healthy donors were used as the positive controls. Fig. 5 shows that both the cell line and cells from primary cultures were more active than the monocytes in 


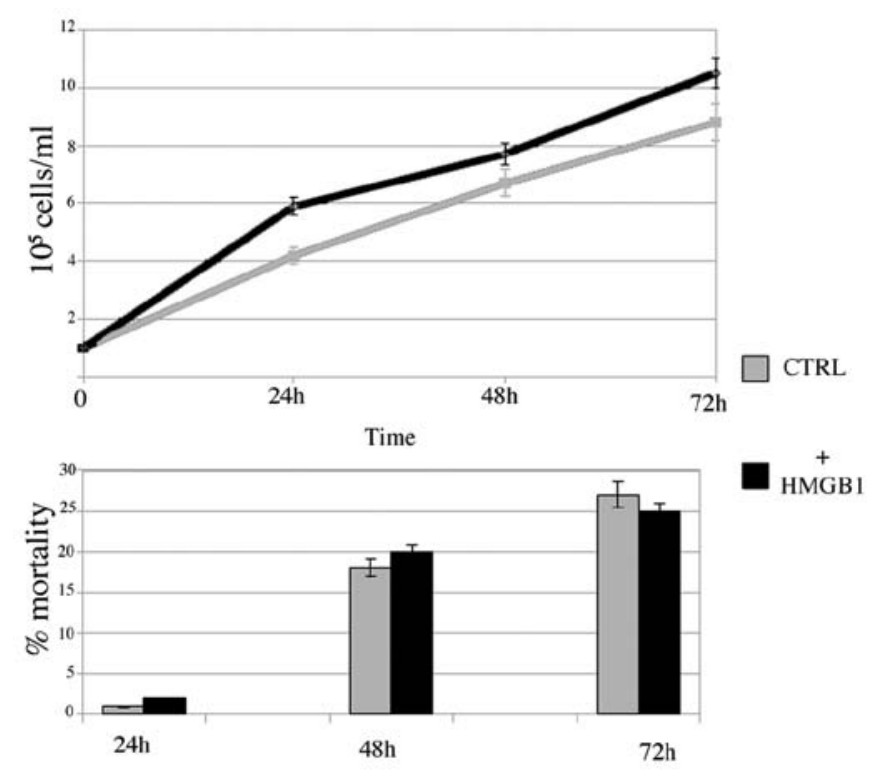

Figure 4. BC PAP cell growth. Cells were grown in RPMI with or without [control cells (CTRL)] HMGB1 for up to $72 \mathrm{~h}$. At the indicated times the cells were counted in duplicate in a Thoma haemocytometer. Cell mortality determined with Trypan blue exclusion test is expressed as the percentage (\%) of dead cells \pm SD.

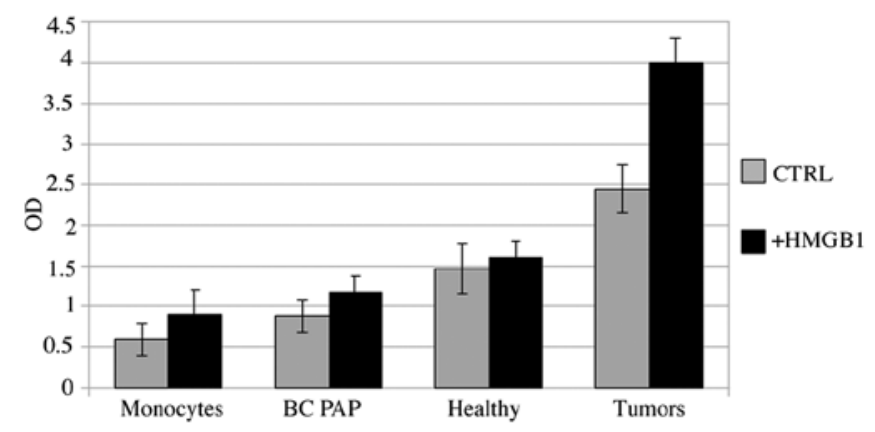

Figure 5. Cell migration in BC PAP cells, primary cultures of papillary cancer, healthy thyreocytes from contralateral lobes and monocytes from healthy donors. Where indicated HMGB1 was added to the lower well of the chemotactic chamber. Results are expressed as optical density (OD) values.

terms of movement through the membranes. This phenomenon was more pronounced in the cells obtained from the patients than in the BC PAP cells and was more evident with the addition of HMGB1, suggesting that HMGB1 attracts tumor cells.

\section{Discussion}

This study reports on a way of signaling between the inflammatory microenvironment (1) of papillary thyroid cancer and the P13K/AKT/PTEN oncogenic pathway. Due to difficulty in obtaining primary cultures, most studies available on cell migration in thyroid cancer have used cell lines; however, our results obtained from primary cultures were similar to those obtained in the cell line.

We demonstrate that the binding of HMGB1 to RAGE increases the expression of miR-221 and -222 in the tumor samples and the cell line. Papillary cancer is highly differentiated and it very rarely metastasizes. However, there are some cases in which the clinical management of patients is difficult, as the tumors remain very small in size but still lead to metastases. Cell growth and motility are often evaluated as malignancy scores in many oncology studies. In this study, we show that the expression of miR-222/-221 is increased in pT3 samples, suggesting that there is a direct correlation between the degree of malignancy and oncogenic cluster expression.

The same correlation was observed between cell motility and HMGB1. This means that a higher number of cells of more malignant phenotype migrated as opposed to cytokines.

HMGB1 in cancer is associated with invasion and metastasis through the high variety of RAGE transduction pathways. These include the activation of NFאB, MAPKs, PI3K/Akt, Rho GTPases, JAK/STAT and Src family kinases. Many tumor suppressor genes such as p53 and PTEN (17) are involved in the RAGE transduction network as essential regulators of the cell cycle. PI3K generates phosphatidylinositol-3,4, 5-triphosphate (PIP3) from phosphatidylinositol 4,5-bisphosphate (PIP2), which then activates Akt. PTEN dephosphorylates PIP3 to inhibit Akt activation (18). PTEN mutations enhance Akt activity in certain cancer cells (19).

Akt activation and decreased PTEN function have been observed in liver cancer (20). A recent study on miRs showed that TGF $\beta$ activates AKT kinase through PTEN downregulation by miR-216 and -217 (21). Since PTEN is a potential target of miR-221 (22) and miR-222, it may constitute a a link between cytokine external signaling and Akt activation. Of note, miR-221 and miR-222 respond to cellular stresses, such as radiation by activating $\mathrm{NF} \kappa \mathrm{B}$ and $\mathrm{AP} 1$ promoters (23).

The results from the present study suggest that the abnormal expression of miR-221 and -222 promoted by HMGB1 may interfere with the PTEN regulation of the cell cycle. Further studies on PTEN inhibition by miR-221 and -222 are required to confirm this hypothesis.

\section{Acknowledgements}

The authors would like to thank Professor Hugo Bowles from Tor Vergata University of Rome for language proofreading. This study was supported by grant Ateneo 60\% (2009) to Professor Alfredo Antonaci and Ateneo 60\% (2011) to Dr Alessandra Zicari.

\section{References}

1. Mardente S, Zicari A, Consorti F, Mari E, Di Vito M,Leopizzi M, Della Rocca C and Antonaci A: Cross-talk between NO and HMGB1 in limphocytic thyroiditis and papillary thyroid cancer. Oncol Rep 24: 1455-1461, 2010.

2. Pikarsky E, Porat RM, Stein I, Abramovitch R, Amit S, Kasem S, Gutkovich-Pyest E, Urieli-Shoval S, Galun E and Ben-Neriah Y: $\mathrm{NF}-\kappa \mathrm{B}$ funtions as a tumor promoter in inflammation-associated cancer. Nature 431: 261-266, 2004.

3. Mardente S, Lenti L, Lococo E, Consorti F, Della Rocca C, Romeo S, Misasi R and Antonaci A: Phenotypic and functional characterization of lymphocytes in autoimmune thyroiditis and in papillary carcinoma. Anticancer Res 25: 2483-2488, 2005.

4. Van Beijnum JR, Buurman WA and Griffioen AW: Convergence and amplification of toll-like receptor (TLR) and receptor for advanced glycation end products (RAGE) signaling pathways via high mobility group B1 (HMGB1). Angiogenesis 11: 91-99, 2008 . 
5. Galardi S, Mercatelli N, Farace MG and Ciafrè SA: NF-kB and c-Jun induce the expression of the oncogenic miR-221 and miR-222 in prostate carcinoma and glioblastoma cells. Nucleic Acids Res 39: 3892-3902, 2011.

6. Palumbo R, De Marchis F, Pusterla T, Conti A, Alessio M and Bianchi ME: Src family kinases are necessary for cell migration induced by extracelllular HMGB1. J Neurooncol 86: 617-623, 2009.

7. Toure F, Zahm JM, Garnotel R, Lambert E, Bonnet N, Schmidt AM, Vitry F, Chanard J, Gillery P and Rieu P: Receptor for advanced glycation end-products (RAGE) modulates neutrophil adhesion and migration on glycoxidated extracellular matrix. Biochem J 416: 255-261, 2008.

8. Kim JY, Park HK, Yoon JS, Kim SJ, Kim ES, Ahn KS, Kim DS, Yoon SS Kim BK and Lee YY: Advanced glycation end product (AGE)-induced proliferation of HEL cells via receptor for AGE-related signal pathways. Int J Oncol 33: 493-501, 2008.

9. Maehama T and Dixon JE: PTEN: a tumour suppressor that functions asa phospholipid phosphatase. Trends Cell Biol 9: 125-128, 1999.

10. Si ML, Zhu S, Wu H, Wu F and Mo YY: miR-21-mediated tumor growth. Oncogene 26: 2799-2803, 2007.

11. Ma L, Teruya-Feldstein J and Weinberg RA: Tumour invasion and metastasis initiated by microRNA-10b in breast cancer. Nature 449: 682-688, 2007

12. Bartel DP: MicroRNAs: target recognition and regulatory functions. Cell 136: 215-233, 2009.

13. He H, Jazdzewski K, Li W, Liyanarachchi S, Nagy R, Volinia S, Calin GA, Liu CG, Franssila K, Suster S, Kloos RT, Croce CM and de la Chapelle A: The role of microRNA genes in papillary thyroid carcinoma. Proc Natl Acad Sci USA 102: 1975-1980, 2005.

14. Visone R, Russo L, Pallante P, De Martino I, Ferraro A, Leone V, Borbone E, Petrocca F, Alder H, Croce CM and Fusco A: MicroRNAs (miR)-221 and miR-222, both overexpressed in human thyroid papillary carcinomas, regulate $\mathrm{p} 27^{\mathrm{Kipl}}$ protein levels and cell cycle. Endocr Relat Cancer 14: 791-798, 2007.
15. Chun-Zhi Z, Lei H, An-Ling Z, Yan-Chao F, Xiao Y, Guang-Xiu W, Zhi-Fan J, Pei-Yu P, Qing-Yu Z and Chun-Sheng K: MicroRNA-221 and microRNA-222 regulate gastric carcinoma cell proliferation and radioresistance by targeting PTEN. BMC Cancer 10: 367, 2010.

16. Fabien N, Fusco A, Santoro M, Barbier Y, Dubois PM and Paulin C: Description of a human papillary thyroid carcinoma cell line. Morphologic study and expression of tumoral markers. Cancer 15: 2206-2212, 1994.

17. Hummel R, Hussey DJ and Haier J: MicroRNAs: predictors and modifiers of chemo- and radiotherapy in different tumour types. Eur J Cancer 46: 298-311, 2010.

18. Cully, M, You, H, Levine AJ and Mak TW: Beyond PTEN mutations: the PI3K pathway as an integrator of multiple inputs during tumorigenesis. Nat Rev Cancer 6: 184-192 2006.

19. Li Q, Li M, Wang YL, Fauzee NJ, Yang Y, Pan J, Yang L and Lazar A: RNA interference of PARG could inhibit the metastatic potency of colon carcinoma cells via PI3-kinase/Akt pathway. Cell Physiol Biochem 29: 361-372, 2012.

20. Wong QW, Ching AK, Chan AW, Choy KW, To KF, Lai PB and Wong N: MiR-222 overexpression confers cell migratory advantages in hepatocellular carcinoma through enhancing AKT signaling. Clin Cancer Res 16: 867-875, 2010.

21. Kato M, Putta S, Wang M, Yuan H, Lanting L, Nair I, Gunn A, Nakagawa Y, Shimano H, Todorov I, Rossi JJ and Natarajan R: TGF-beta activates Akt kinase through a microRNA-dependent amplifying circuit targeting PTEN. Nat Cell Biol 11: 881-889, 2009.

22. Meng $F$, Henson $R$, Lang $M$, Wehbe $H$, Maheshwari $S$, Mendell JT, Jiang J, Schmittgen TD and Patel T: Involvement of human micro-RNA in growth and response to chemotherapy in human cholangiocarcinoma cell lines. Gastroenterology 130: 2113-2129, 2006

23. Vincenti S. Brillante N, Lanza V, Bozzoni I, Presutti C, Chiani F, Etna MP and Negri R: HUVEC respond to radiation by inducing the expression of pro-angiogenic microRNAs. Radiat Res 175: 535-546, 2011. 